\title{
Utilization of Subcutaneous Methotrexate in Rheumatoid Arthritis Patients After Failure or Intolerance to Oral Methotrexate: A Multicenter Cohort Study
}

Jaime C. Branco · Anabela Barcelos · Filipe Pombo de Araújo · Graça Sequeira • Inês Cunha · José Vaz Patto • Margarida Oliveira $\cdot$ Margarida Pratas Mateus $\cdot$ Maura Couto $\cdot$ Patrícia Nero $\cdot$ Patrícia Pinto $\cdot$ Paulo Monteiro Walter Castelão $\cdot$ Jorge Félix $\cdot$ Diana Ferreira $\cdot$ João Almeida $\cdot$ Maria João Silva

To view enhanced content go to www.advancesintherapy.com Received: October 12, 2015 / Published online: January 2, 2016

(C) The Author(s) 2016. This article is published with open access at Springerlink.com

\begin{abstract}
Introduction: Low-dose weekly methotrexate (MTX) is the mainstay in the therapy of rheumatoid arthritis (RA). It can be given via oral, intramuscular or subcutaneous (SC) route. This study sought to determine the real-world pattern of treatment with SC MTX in Portuguese adult patients with active RA.
\end{abstract}

Electronic supplementary material The online version of this article (doi:10.1007/s12325-015-0276-3) contains supplementary material, which is available to authorized users.

J. C. Branco $(\bowtie)$

CEDOC-Nova Medical School, Faculdade de

Ciências Médicas da Universidade de Lisboa, Lisbon, Portugal

e-mail: jaime.branco@nms.unl.pt

A. Barcelos · I. Cunha

Centro Hospitalar do Baixo Vouga, E.P.E., Hospital

Infante D. Pedro, Aveiro, Portugal

F. P. de Araújo - M. P. Mateus · P. Nero · W. Castelão

Centro Hospitalar de Lisboa Ocidental, E.P.E.,

Hospital de Egas Moniz, Lisbon, Portugal

G. Sequeira

Hospital de Faro, E.P.E., Faro, Portugal

J. V. Patto

Instituto Português de Reumatologia, Lisbon,

Portugal
Methods: Utilization of Metoject $^{\circledR}$ in Rheumatoid Arthritis (UMAR) was a non-interventional, cohort multicenter study with retrospective data collection. Eligible patients had active RA, at least 18 years of age, and started SC MTX treatment in 2009 or 2010 after failure or intolerance to oral MTX. Data were collected from patient's clinical records. Both non-parametric and parametric survival methods were used to obtain a detailed understanding of SC MTX treatment duration. Result: Fifty patients were included, of which only 9 discontinued SC MTX during the study

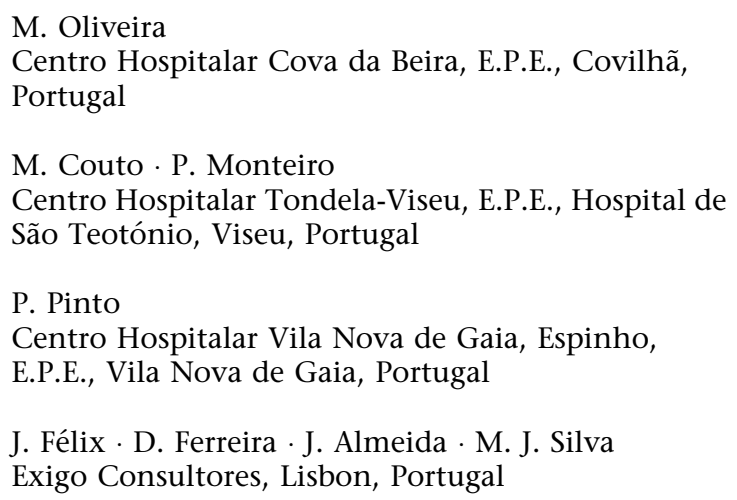


follow-up period. The probability of discontinuation after 1, 2, and 3 years of treatment of SC MTX treatment is expected to be $6.10 \%, 8.50 \%$, and $23.20 \%$, respectively. The extrapolated median duration of SC MTX using an exponential model was 106.4 months/ 8.87 years. Mean dose of SC MTX was $18.36 \mathrm{mg}$. The reasons for treatment discontinuation were occurrence of adverse events in six patients and lack of efficacy in three.

Conclusion: The long treatment duration of SC MTX highlights its excellent tolerability compared to oral MTX, especially concerning the frequent adverse gastrointestinal events of MTX. Furthermore, long MTX treatment duration provides the opportunity to postpone or even avoid expensive therapies with biologics. The results obtained from the UMAR study provide important information for the utilization and public financing of SC MTX in Portugal.

Keywords: Continuation rates; Methotrexate; Methotrexate failure; Oral treatment; Rheumatoid arthritis; Subcutaneous methotrexate; Subcutaneous treatment; Treatment duration; UMAR

\section{INTRODUCTION}

The goal of rheumatoid arthritis (RA) treatment is to prevent joint damage, decrease pain, prevent functional impairment, and maintain or improve quality of life [1]. Currently, the use of disease-modifying antirheumatic drugs (DMARDs) is recommended as soon as the diagnosis is made to decrease or prevent disease progression and severity. However, the optimal therapeutic effect mediated by DMARDs is usually obtained after 4 to 6 months [2].
As methotrexate (MTX) is a highly effective DMARD with a favorable efficacy/safety profile [3], the S1 guideline for sequential medical treatment of active RA recommends that MTX should be administered before other DMARDs [4]. The advantage of subcutaneous (SC) MTX treatment is the linear dose absorption, which potentially improves the efficacy of SC MTX compared to oral administration of the same dosage [5]. Evidence of better efficacy and less gastrointestinal (GI) toxicity with parenteral versus oral MTX supports the recommendation of the Canadian Rheumatology Association and the Finnish Current Care Guidelines (Käypä hoito) to start treatment with SC MTX in DMARD naïve RA patients [6, 7]. Nonetheless, oral MTX is still the preferred treatment route $[4,8]$. When oral MTX treatment failure occurs, clinical practice has been to switch to other agents, such as biological DMARDs. MTX SC administration might be an alternative before switching or adding other DMARDs in the treatment of RA.

The aim of the Utilization of Metoject ${ }^{\circledR}$ in Rheumatoid Arthritis (UMAR) study was to determine the median duration of SC MTX treatment in Portuguese adult patients with active RA. Treatment of active RA with SC MTX was introduced after failure or intolerance to oral MTX. In this multicenter cohort study, treatment duration was defined as the time between beginning and discontinuation of SC MTX treatment.

\section{MATERIALS AND METHODS}

\section{Study Design}

UMAR was a non-interventional, noncomparative, multicenter cohort study with retrospective data collection. 


\section{Study Medication}

The Study drug was a commercially available MTX pre-filled syringe $(10 \mathrm{mg} / \mathrm{ml}$ solution for SC injection; Metoject $^{\circledR}$ in Germany, manufacturer: medac Gesellschaft für klinische Spezialpräparate mbH, Hamburg, Germany). SC MTX was prescribed after failure or intolerance to oral MTX, according to the criteria defined by the Sociedade Portuguesa de Reumatologia (Portuguese Society of Rheumatology) [9].

\section{Clinical Setting}

Seven Portuguese rheumatology departments were involved in this study: Centro Hospitalar de Lisboa Ocidental, E.P.E./Hospital de Egas Moniz, Lisboa, Instituto Português de Reumatologia, Lisboa, Centro Hospitalar do Baixo Vouga, E.P.E./ Hospital Infante D. Pedro, Aveiro, Centro Hospitalar Vila Nova de Gaia/Espinho, E.P.E., Hospital de Faro, E.P.E., Centro Hospitalar Cova da Beira, E.P.E., Covilhã, Centro Hospitalar Tondela-Viseu, E.P.E./Hospital de São Teotónio.

\section{Study Population}

Eligible patients were at least 18 years of age and had been diagnosed with active RA by expert opinion. All eligible patients who had started treatment with SC MTX in 2009 or 2010 were included at each site. Eligibility was validated by the investigators of the research centers involved. After written informed consent was granted by the patients, investigators filled out standardized questionnaires using data from the participants' clinical records.

\section{Variables}

Patient variables assessed in this study included age, gender, education, profession, and professional status. RA and treatment variables included disease duration, treatment duration, mean dose, and reasons for treatment discontinuation.

\section{Data Collection}

Starting on December 28th 2011, data were collected retrospectively over a period of 3 to 4 months in each research center from the participants' clinical records. The median time between the initiation of oral MTX and the end of SC MTX therapy or last information available was 6.97 years (range 0.85-21.60).

\section{Analytical Plan}

Data from questionnaires were transcribed into an electronic database. Validation of this information was performed through its re-introduction: a sample of $50 \%$ of the questionnaires was transcribed again by the same individuals and compared with the initial introduction.

\section{Statistical Analysis}

Statistical analysis included the estimation of absolute and relative frequencies, mean values, and standard errors. Concerning the analysis of time to discontinuation of SC MTX, it was considered that (1) treatment interruptions of 3 months or less followed by drug reintroduction did not constitute discontinuation.

(2) Discontinuations caused by lack of efficacy or adverse events or due to the patient's will were considered events, except for the case of patient pregnancy. (3) SC MTX treatment persistence at each patient's medical data review including association with biologic agents or other DMARDs, involuntary discontinuations (drug not available at the 
pharmacy) or discontinuations due to pregnancy were considered censored observations. Censoring is said to occur when it is not possible to observe the event of interest during the study period. Survival analysis methods were performed to study the time until the occurrence of pre-specified events, e.g. introduction of SC MTX or discontinuation of SC MTX treatment. Data regarding the duration of SC MTX treatment included censored observations. For oral MTX we estimate treatment duration prior to SC MTX, reasons for discontinuation, and oral MTX doses. The Kaplan-Meier estimator one of the non-parametric estimators most commonly used to estimate the survival function in the presence of censored observations and, along with non-parametric methods, it was used in this study.

Non-parametric methods are reasonably easy to apply and avoid certain assumptions about data behavior. However, they are less effective than parametric methods regarding extrapolation of times exceeding the time horizon considered in the study. Thus, this analysis considered the following parametric methods: exponential, Weibull, log-logistic, and log-normal models [10].

Statistical analysis was performed using STATA version 10.1 (StataCorp, 2007, Texas, USA) and R-package version 2.15.1 (R Core Team, 2012, Vienna, Austria) software.

\section{Compliance with Ethics Guidelines}

This article is based on previously conducted studies and does not involve any new studies of human or animal subjects performed by any of the authors. Additional informed consent was obtained from all patients for whom identifying information is included in this article.
All procedures followed were in accordance with the ethical standards of the responsible committee on human experimentation (institutional and national) and with the Helsinki Declaration of 1964, as revised in 2013.

\section{RESULTS}

A total of 50 patients' medical records were reviewed from the seven research centers that participated in the UMAR study. The main sociodemographic and clinical characteristics of patients included in this analysis are presented in Table 1. Mean [Standard Deviation (SD)] duration of RA at time of data collection was 11.04 (8.00) years, and all participants were treated with oral MTX (first-line treatment) prior to SC MTX.

\section{Oral MTX treatment}

Recorded AE of oral MTX included diarrhea (one patient), gastric intolerance (two patients), malaise (two patients), mucositis (one patient), nausea (three patients), and vomiting (two patients). The main reason for discontinuation of oral MTX was lack of efficacy (69.57\%), followed by the occurrence of AE (28.26\%), and a combination of both (2.17). The characterization of oral MTX treatment is presented in Table 2.

\section{SC MTX}

SC MTX was second-line treatment in 46 of 50 cases (92\%), as suggested by the treatment guidelines from Sociedade Portuguesa de Reumatologia. Four participants (8\%) used other DMARDs after failing oral MTX and prior to SC MTX, two patients were treated with biological drugs: one patient with 
Table 1 Sociodemographic and clinical characteristics of UMAR participants

\begin{tabular}{|c|c|c|}
\hline \multicolumn{2}{|l|}{ Characteristics } & \multirow{2}{*}{$\frac{\text { Missing }(n)}{7}$} \\
\hline Age, years $($ mean $\pm S D)$ & $55.89 \pm 13.03$ & \\
\hline Gender $[n(\%)]$ & & 5 \\
\hline Male & $6(13.33)$ & \\
\hline Female & $39(86.67)$ & \\
\hline Years of education $($ mean $\pm S D)$ & $6.73 \pm 5.32$ & 28 \\
\hline Current professional status $[n(\%)]$ & & 5 \\
\hline Employed & $18(40.00)$ & \\
\hline Unemployed & $3(6.67)$ & \\
\hline Retired & $22(48.89)$ & \\
\hline Due to RA & $11(50.00)$ & \\
\hline Other & $2(4.44)$ & \\
\hline Profession $[n(\%)]$ & & 14 \\
\hline Unskilled workers & $10(27.78)$ & \\
\hline Administrative function or similar & $8(22.22)$ & \\
\hline Technicians or intermediate-level professionals & $4(11.11)$ & \\
\hline Sales or services & $3(8.33)$ & \\
\hline Laborers, craftsmen, or similar & $3(8.33)$ & \\
\hline Intellectual or scientific profession & $3(8.33)$ & \\
\hline Farmers or similar & $2(5.56)$ & \\
\hline Installation or machine operator/assembly worker & $2(5.56)$ & \\
\hline Domestic & $1(2.78)$ & \\
\hline Disease duration, years (mean $\pm S D$ ) & $11.04 \pm 8.00$ & 3 \\
\hline
\end{tabular}

$S D$ standard deviation, UMAR Utilization of Metoject ${ }^{\circledR}$ in Rheumatoid Arthritis

intravenous MTX and another patient with hydroxychloroquine. On average (SD), SC MTX was initiated 8.5 (8.1) years after the diagnosis of RA and 5.3 (4.4) years after the start of oral MTX, with an estimated median time of 6.9 years (Fig. 1a) and 4.3 years (Fig. 1b), respectively. The four patients who used other drugs as a second-line treatment had a mean (SD) period of 2.5 (1.6) years until the start of SC MTX.
Mean dose and individual dosages of SC MTX treatment are shown in Table 2. The median time until first dosage adjustment was 651 days (21.4 months) as presented in Fig. 2. Twenty-three participants remained on the same dose of SC MTX, while eight (29.6\%) and seventeen (70.4\%) patients had a downward and an upward dose adjustment, respectively. Only two patients presented more than one dosage adjustment: for one, SC MTX dose was 
Table 2 Characteristics of oral methotrexate prior to subcutaneous methotrexate treatment and subcutaneous methotrexate utilization in UMAR study

\begin{tabular}{lll}
\hline Characteristics & & Missing $(\boldsymbol{n})$ \\
\hline Oral methotrexate & & 3 \\
Duration, months $($ mean $\pm \mathrm{SD})$ & $14.84 \pm 53.32 \pm 0.46$ & 4 \\
Mean dose (mean $\pm \mathrm{SD})$ & \\
Reason for treatment discontinuation $[n(\%)]$ & $13(28.26)$ \\
Adverse events & $32(69.57)$ \\
Lack of efficacy & $1(2.17)$ \\
Adverse events and other & \\
Subcutaneous methotrexate & $18.36 \pm 0.53$ \\
Mean dose, mg (mean \pm SD) & \\
Dose, mg $[n(\%)] ;$ mean duration (months) & $1(2.00) ; 3.68$ \\
8 & $11(22.00) ; 14.72$ \\
10 & $24(48.00) ; 17.02$ \\
15 & $31(62.00) ; 15.63$ \\
20 & $12(24.00) ; 24.08$ \\
25 & \\
Reason for treatment discontinuation $[n(\%)]$ & $6(66.67)$ \\
Adverse events & $2(22.22)$ \\
Lack of efficacy & $1(11.11)$ \\
Other &
\end{tabular}

The sum differs $(9=100 \%)$ since one participant discontinued the treatment due to more than one reason $S D$ standard deviation, UMAR Utilization of Metoject ${ }^{\circledR}$ in Rheumatoid Arthritis

changed for three times until discontinuation due to adverse events; the other is still being treated with SC MTX at the time of data collection.

During treatment with SC MTX, nine patients were treated with biological agents (TNF inhibitors and tocilizumab) or other DMARDs (hydroxychloroquine, leflunomide, and sulfasalazine). SC MTX dose was reduced from 25 to $15 \mathrm{mg}$ in one patient but in the other eight the dose remained unchanged during the association period. Three patients had stopped biological treatment and of those only one had discontinued SC MTX at the time of data collection.

After discontinuation of SC MTX treatment, patients maintained treatment with other parenteral MTX, oral MTX, leflunomide, or association between synthetic and biological DMARDs (abatacept, adalimumab, and etanercept).

In order to assess UMAR's endpoint, the duration of SC MTX treatment of all participants was evaluated regardless of dose changes during this period. Forty-one out of 50 patients were considered censored observations 


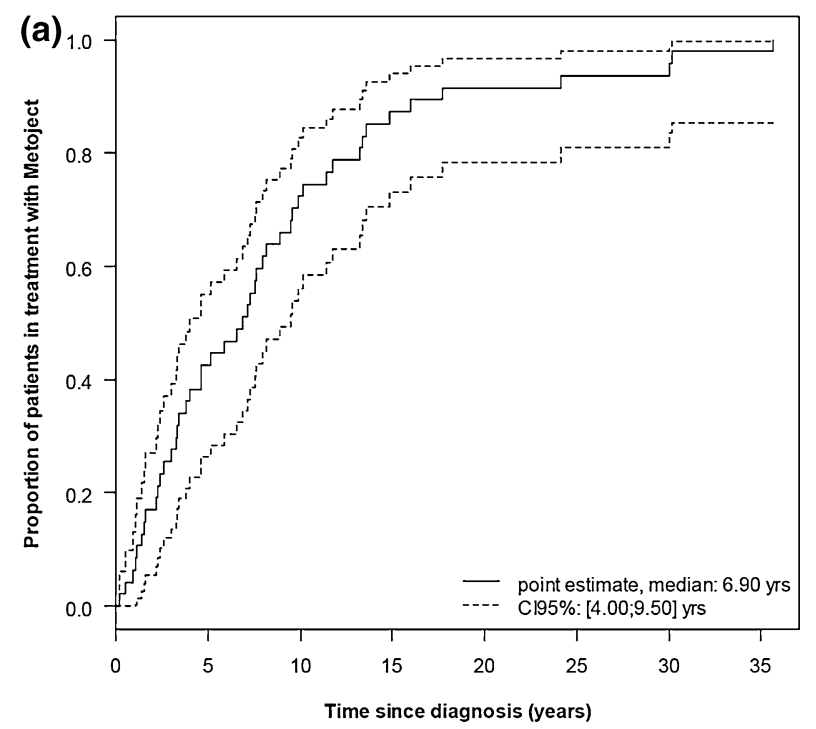

Fig. 1 a Kaplan-Meier estimate of time between diagnosis of RA and the beginning of subcutaneous methotrexate treatment (time in years); b Kaplan-Meier estimate for time from the beginning of oral methotrexate treatment to

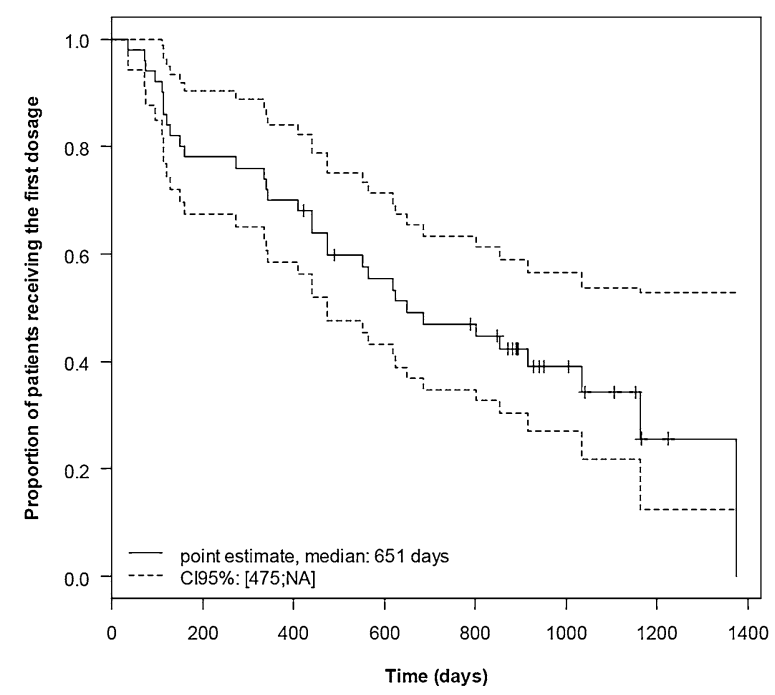

Fig. 2 Kaplan-Meier estimate for time until first subcutaneous methotrexate dosage adjustment (time in days). CI confidence interval

(37 patients were still treated with SC MTX at the time of data collection and 4 patients had stopped SC MTX due to pregnancy or drug shortage). SC MTX discontinuation was recorded for only nine patients and was

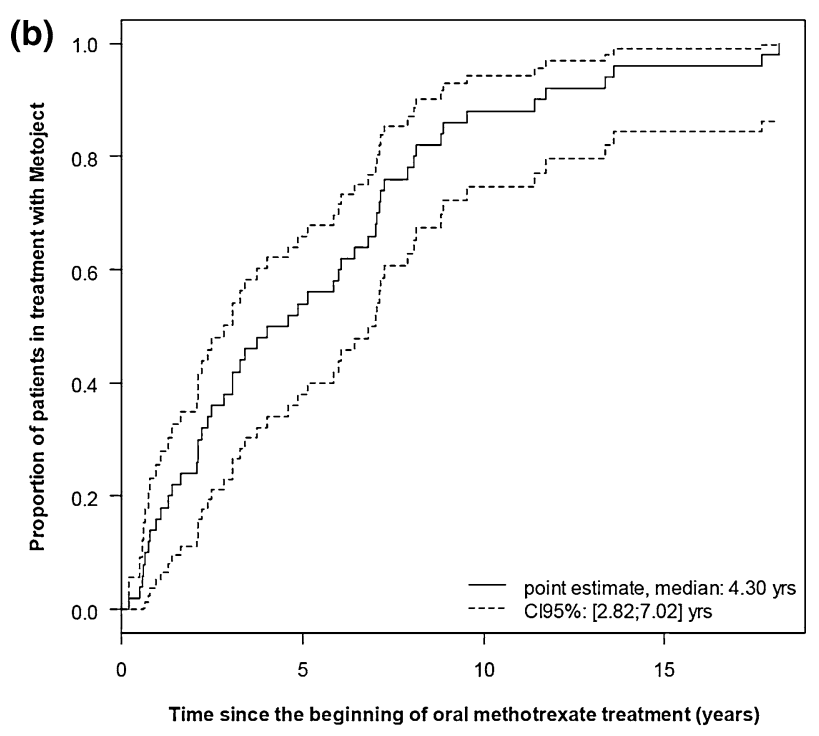

the beginning of subcutaneous methotrexate treatment (time in years). $R A$ rheumatoid arthritis, $C I$ confidence interval

mainly a consequence of AEs (66.7\%). Lack of efficacy was the cause of stopping SC MTX treatment in only three patients (Table 2). Due to the low number of occurrences and the short follow-up period, median time until SC MTX discontinuation was not observed (Fig. 3a). The data collected suggest that the probability of discontinuation after 1,2 , and 3 years of treatment is expected to be $6.1 \%$ (CI 95\%: 0-9.5\%), 8.5\% (CI 95\%: 0.1-16.1\%), and 23.2\% (CI 95\%: 5.3-37.7\%), respectively. Globally, the probability of UMAR participants remaining in treatment with MTX (oral and SC) over 5 years was $82.7 \%$ based upon Kaplan-Meier estimation.

To obtain predictions for the median duration of SC MTX treatment, parametric methods for survival analysis were used. For this purpose, several parametric models were adjusted to the data (Table 3; Fig. 3b). Various estimates for the median time until SC MTX discontinuation were obtained (72.1-114.8 months) depending on the type of 


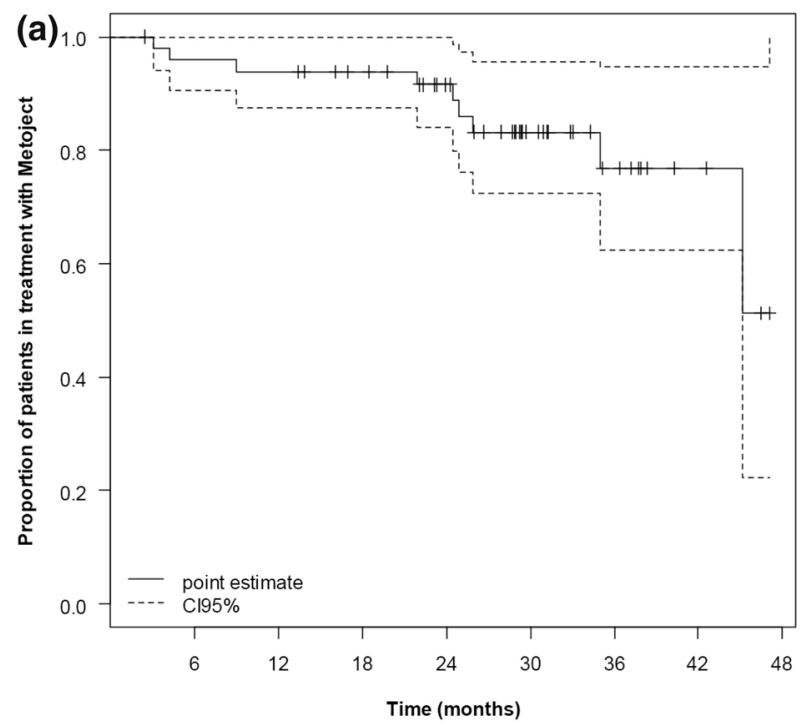

Fig. 3 a Kaplan-Meier estimation for the time until subcutaneous methotrexate treatment discontinuation by UMAR participants (time in months). b Kaplan-Meier estimate and parametric fits for time until subcutaneous

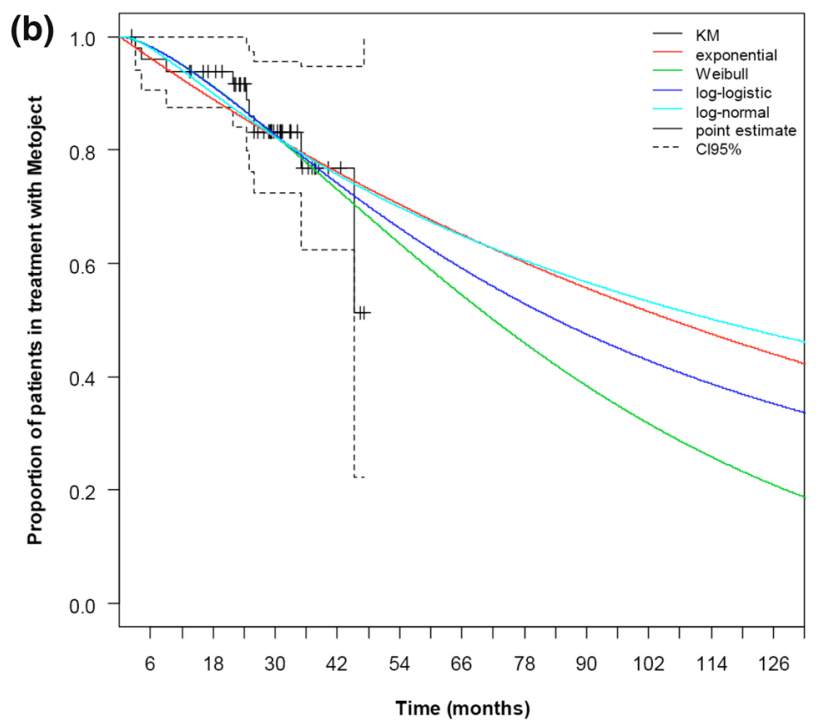

methotrexate discontinuation by UMAR participants (time in months). UMAR Utilization of Metoject ${ }^{\circledR}$ in Rheumatoid Arthritis, $C I$ confidence interval, $K M$ Kaplan-Meier

Table 3 Estimation of the median time until subcutaneous methotrexate discontinuation, assuming different distributions

\begin{tabular}{lll}
\hline Distribution of time until discontinuation & Median time (months) & AIC \\
\hline Exponential & 106.41 (95\% CI: 55.37-204.52) & 172.09 \\
Weibull & 72.14 (95\% CI: 36.93-140.91) & 172.78 \\
Log-logistic & 84.24 (95\% CI: 38.64-183.68) & 173.18 \\
Log-normal & 114.80 (95\% CI: 41.95-314.14) & 174.00 \\
\hline
\end{tabular}

$A I C$ akaike information criterion, $C I$ confidence interval

distribution assumed. Table 3 presents the Akaike information criterion (AIC), to provide information on the goodness of fit of the respective parametric model. The parametric distribution showing the minimum AIC is the exponential distribution, representing a median duration of SC MTX treatment of 106.41 months (8.87 years).

\section{DISCUSSION}

The UMAR study investigated the duration of SC MTX treatment of 50 eligible Portuguese patients with active RA. The probability of discontinuation after 1, 2, and 3 years of treatment of SC MTX treatment is expected to be $6.10 \%, 8.50 \%$, and $23.20 \%$, respectively. Only nine (18\%) patients discontinued SC MTX treatment during the observation period. The UMAR study revealed a long median duration of SC MTX treatment of 106.4 months (8.9 years) according to the exponential distribution $\quad(\mathrm{AIC}=172.1)$. In purely statistical terms, the exponential distribution represents the best fit to time to SC MTX discontinuation because it minimizes 
the AIC value. However, AIC values for the other distributions do not differ very much and these other distributions may also be considered. UMAR is the first study to address the median duration of SC MTX treatment in clinical practice.

In a post-marketing surveillance study, the tolerability and usability of self-administered high-dose SC MTX was tested for 5 weeks in patients with RA or psoriatic arthritis [11]. The formulation was generally well tolerated. Furthermore, 221 (54.8\%) patients had previously received MTX treatment at dosages between 7.5 and $25 \mathrm{mg}$ /week for up to 23 years. SC MTX was administered to $92(41.6 \%)$ of these patients. The duration of up to 23 years is a noteworthy period of time of SC MTX treatment, and it proves its excellent tolerability. SC MTX dose was maintained or reduced whenever other DMARDs were added to the treatment. The combination of other DMARDs with SC MTX is more effective than the monotherapy with these agents [12-17]. Although the efficacy of SC MTX was not evaluated in the UMAR study, published evidence reveals the superiority of SC over oral MTX [3, 17]. Moreover, SC MTX has demonstrated the potential to reduce GI adverse events compared to the oral treatment [18].

In UMAR, the mean duration of oral MTX treatment prior to the SC formulation was 55.8 months, which we were unable to compare with other published studies since they lack this information. However, during this period, the mean weekly oral MTX dose of $14.3 \mathrm{mg}$ was in accordance with the published values of 12.4-19.0 mg [19-21]. The literature also reveals a tendency towards the utilization of higher doses, probably due to differing levels of RA severity [19, 22-25]. The main reason for discontinuation of oral MTX was lack of efficacy. In our study, discontinuation of SC
MTX was more frequently due to AE than to lack of efficacy. UMAR participants reported several AEs related to oral MTX, predominantly GI AEs, which are well-known complications of this treatment [26]. However, as these data were collected separately, it cannot be assumed that the previously reported AEs were the reason of oral MTX discontinuation due to AEs.

Due to the limited patient follow-up this study presented only a small number of discontinuation events. For this reason, extrapolation using parametric survival models was required. Longer follow-up periods are recommended for future studies. The UMAR enquiry was subject to the usual limitations of a retrospective study: selection bias, information bias, and other problematic variables. Also results should be interpreted in light of the small sample size.

\section{CONCLUSION}

The UMAR research project provided unprecedented information related to the utilization of SC MTX. Of particular significance is that treatment duration and administered dose of SC MTX were investigated for the very first time. The long treatment period presented in this study suggests a superior tolerability profile, as well as efficacy of SC MTX. Furthermore, it allows postponing or even avoiding expensive treatments with biological drugs, representing a potential considerable financial saving that could ultimately lead to a reduction of the financial burden on the Portuguese healthcare system.

\section{ACKNOWLEDGMENTS}

This study was funded by medac GmbH (Wedel, Germany) and Medinfar (Algés, Portugal) and 
the article publication charges and charges for medical writing by Juliane Schreier and Marc Esser, co.faktor $\mathrm{GmbH}$ (Belin, Germany) were funded by medac GmbH (Wedel, Germany). All named authors meet the International Committee of Medical Journal Editors (ICMJE) criteria for authorship for this manuscript, take responsibility for the integrity of the work as a whole, and have given final approval for the version to be published.

Author contribution. JCB, JF, DF, JA, and MJS contributed to the study design; JCB, AB, FPA, GS, IC, JVP, MO, MPM, MC, PN, PP, PM, and WC contributed to data collection; MJS was responsible for data analysis; JF, DF, JA, and MJS contributed to data interpretation; All named authors meet the International Committee of Medical Journal Editors (ICMJE) criteria for authorship for this manuscript, take responsibility for the integrity of the work as a whole, and have given final approval to the version to be published. We thank Dr. J. Schreier and Dr. M. Esser (co.faktor, Berlin, Germany) for medical writing.

Disclosures. Jorge Félix has received consulting fees from medac GmbH. Diana Ferreira has received consulting fees from medac GmbH. João Almeida has received consulting fees from medac GmbH. Maria João Silva has received consulting fees from medac GmbH. Jaime C. Branco, Anabela Barcelos, Filipe Pombo de Araújo, Graça Sequeira, Inês Cunha, José Vaz Patto, Margarida Oliveira, Margarida Pratas Mateus, Maura Couto, Patrícia Nero, Patrícia Pinto, Paulo Monteiro and Walter Castelão have nothing to disclose.

Compliance with ethics guidelines. This article is based on previously conducted studies and does not involve any new studies of human or animal subjects performed by any of the authors. Additional informed consent was obtained from all patients for whom identifying information is included in this article. All procedures followed were in accordance with the ethical standards of the responsible committee on human experimentation (institutional and national) and with the Helsinki Declaration of 1964, as revised in 2013.

Open Access. This article is distributed under the terms of the Creative Commons Attribution-NonCommercial 4.0 International License (http://creativecommons.org/licenses/ by-nc/4.0/), which permits any noncommercial use, distribution, and reproduction in any medium, provided you give appropriate credit to the original author(s) and the source, provide a link to the Creative Commons license, and indicate if changes were made.

\section{REFERENCES}

1. ACRSRAG: American College of Rheumatology Subcommittee on rheumatoid arthritis guidelines. Guidelines for the management of rheumatoid arthritis-2002 update. Arthritis Rheum. 2002;46(2):328-46.

2. Smolen JS, Landewé R, Breedveld F, et al. EULAR recommendations for the management of rheumatoid arthritis with synthetic and biological disease-modifying antirheumatic drugs: 2013 update. Ann Rheum Dis. 2014;73:492-509.

3. Braun J, Kästner P, Flaxenberg P, et al. Comparison of the clinical efficacy and safety of subcutaneous versus oral administration of methotrexate in patients with active rheumatoid arthritis: results of a six-month, multicentre, randomized, double-blind, controlled, phase IV trial. Arthritis Rheum. 2008;58(1):73-81.

4. Krüger K, Wollenhaupt J, Albrecht K, et al. German guidelines for the sequential medical treatment of rheumatoid arthritis 2012: adapted EULAR recommendations and update of a treatment algorithm [S1-Leitlinie der DGRh zur sequenziellen 
medikamentösen Therapie der rheumatoiden Arthritis 2012: adaptierte EULAR Empfehlung und aktualisierter Therapiealgorithmus]. Z Rheumatol. 2012;71(7):592-603.

5. Schiff MH, Jaffe JS, Freundlich B. Head-to-head, randomised, crossover study of oral versus subcutaneous methotrexate in patients with rheumatoid arthritis: drug-exposure limitations of oral methotrexate at doses $\geq 15 \mathrm{mg}$ may be overcome with subcutaneous administration. Ann Rheum Dis. 2014;73:1549-51.

6. Wegrzyn J, Adeleine P, Miossec P. Better efficacy of methotrexate given by intramuscular injection than orally in patients with rheumatoid arthritis. Ann Rheum Dis. 2004;63(10):1232-4.

7. Bykerk VP, Akhavan P, Hazlewood GS, et al. Canadian Rheumatology Association recommendations for pharmacological management of rheumatoid arthritis with traditional and biologic diseasemodifying antirheumatic drugs. J Rheumatol. 2012;39(8):1559-82.

8. Smolen JS, Landewé R, Breedveld FC, et al. EULAR recommendations for the management of rheumatoid arthritis with synthetic and biological disease-modifying antirheumatic drugs. 2013 update. Ann Rheum Dis. 2014;73(3):492-509.

9. Fonseca JE, Bernardes $\mathrm{M}$, Canhao $\mathrm{H}$, et al. Portuguese guidelines for the use of biological agents in rheumatoid arthritis-October 2011 update. Acta Reumatol Port. 2011;36(4):385-8.

10. Akaike H. Information theory as an extension of the maximum likelihood principle. In: Petrov BN, Csaki $\mathrm{F}$, editors. 2nd international symposium on information theory. Budapest: Akademiai Kiado; 1973. p. 276-81.

11. Striesow F, Brandt A. Preference, satisfaction and usability of subcutaneously administered methotrexate for rheumatoid arthritis or psoriatic arthritis: results of a postmarketing surveillance study with a high-concentration formulation. Ther Adv Musculoskel Dis. 2012;4(1):3-9.

12. Braun J. Methotrexate: optimizing the efficacy in rheumatoid arthritis. Ther Adv Musculoskel Dis. 2011;3(3):151-8.

13. Breedveld FC, Weisman MH, Kavanaugh AF, et al. A multicenter, randomized, double-blind clinical trial of combination therapy with adalimumab plus methotrexate versus methotrexate alone or adalimumab alone in patients with early, aggressive rheumatoid arthritis who had not had previous methotrexate treatment. Arthritis Rheum. 2006;54(1):26-37.
14. Garnero P, Thompson E, Woodworth T, Smolen JS Rapid and sustained improvement in bone and cartilage turnover markers with the anti-interleukin-6 receptor inhibitor tocilizumab plus methotrexate in rheumatoid arthritis patients with an inadequate response to methotrexate: results from a substudy of the multicenter double-blind, placebo-controlled trial of tocilizumab in inadequate responders to methotrexate alone. Arthritis Rheum. 2010;62(1):33-43.

15. Carmichael SJ, Beal J, Day RO, Tett SE. Combination therapy with methotrexate and hydroxychloroquine for rheumatoid arthritis increases exposure to methotrexate. J Rheumatol. 2002;29(10):2077-83.

16. Weinblatt ME, Kremer JM, Coblyn JS, et al. Pharmacokinetics, safety, and efficacy of combination treatment with methotrexate and leflunomide in patients with active rheumatoid arthritis. Arthritis Rheum. 1999;42(7):1322-8.

17. Shiroky JB, Watts CS, Neville C. Combination methotrexate and sulfasalazine in the management of rheumatoid arthritis: case observations. Arthritis Rheum. 1989;32(9): 1160-4.

18. Rutkowska-Sak L, Rell-Bakalarska M, Lisowska B. Oral vs. subcutaneous low-dose methotrexate treatment in reducing gastrointestinal side effects. Reumatologia. 2009;47:207-11.

19. Bathon JM, Martin RW, Fleischmann RM, et al. A comparison of etanercept and methotrexate in patients with early rheumatoid arthritis. N Engl J Med. 2000;343(22):1586-93.

20. Kinder AJ, Hassell AB, Brand J, Brownfield A, Grove M, Shadforth MF. The treatment of inflammatory arthritis with methotrexate in clinical practice: treatment duration and incidence of adverse drug reactions. Rheumatology. 2005;44:61-6.

21. Cronstein BN. Low-dose methotrexate: a mainstay in the treatment of rheumatoid arthritis. Pharmacol Rev. 2005;57(2):163-72.

22. Genovese, MC, Bathon JM, Martin RW et al. Etanercept versus methotrexate in patients with early rheumatoid arthritis: two-year radiographic and clinical outcomes. Arthritis Rheum. 2002;46(6):1443-50.

23. Kremer JM, Lee JK. The safety and efficacy of the use of methotrexate in long-term therapy for rheumatoid arthritis. Arthritis Rheum. 1986;29(7):822-31. 
24. Choi HK, Hernán MA, Seeger JD, Robins JM, Wolfe F. Methotrexate and mortality in patients with rheumatoid arthritis: a prospective study. Lancet. 2002;359:1173-7.

25. Rau R, Simianer S, van Riel PL, et al. Rapid alleviation of signs and symptoms of rheumatoid arthritis with intravenous or subcutaneous administration of adalimumab in combination with methotrexate. Scand J Rheumatol. 2004;33(3):145-53.

26. Neves C, Jorge R, Barcelos A. A teia de toxicidade do metotrexato. Acta Reumatol Port. 2009;34:11-34. 